\title{
Global economic burden of schizophrenia: a systematic review
}

\author{
This article was published in the following Dove Press journal: \\ Neuropsychiatric Disease and Treatment \\ 16 February 2016 \\ Number of times this article has been viewed
}

\author{
Huey Yi Chong' \\ Siew Li Teoh' \\ David Bin-Chia Wu' \\ Surachai Kotirum' \\ Chiun-Fang Chiou ${ }^{2}$ \\ Nathorn Chaiyakunapruk ${ }^{1,3-5}$ \\ 'School of Pharmacy, Monash \\ University Malaysia, Selangor, \\ Malaysia; ${ }^{2} J a n s s e n$ Pharmaceutical \\ Companies Asia Pacific, Singapore; \\ ${ }^{3}$ Center of Pharmaceutical Outcomes \\ Research (CPOR), Department \\ of Pharmacy Practice, Faculty of \\ Pharmaceutical Sciences, Naresuan \\ University, Phitsanulok, Thailand; \\ ${ }^{4}$ School of Pharmacy, University of \\ Wisconsin, Madison, WI, USA; ${ }^{5}$ School \\ of Population Health, University of \\ Queensland, Brisbane, Australia
}

Correspondence: Nathorn Chaiyakunapruk School of Pharmacy, Monash University Malaysia, Jalan Lagoon Selatan, 46I50 Bandar Sunway, Selangor, Malaysia Email nathorn.chaiyakunapruk@monash. edu

submit your manuscript | www.dovepress.com Dovepress http://dx.doi.org/1 0.2147/NDT.S96649
Background: Schizophrenia is one of the top 25 leading causes of disability worldwide in 2013. Despite its low prevalence, its health, social, and economic burden has been tremendous, not only for patients but also for families, caregivers, and the wider society. The magnitude of disease burden investigated in an economic burden study is an important source to policymakers in decision making. This study aims to systematically identify studies focusing on the economic burden of schizophrenia, describe the methods and data sources used, and summarize the findings of economic burden of schizophrenia.

Methods: A systematic review was performed for economic burden studies in schizophrenia using four electronic databases (Medline, EMBASE, PsycINFO, and EconLit) from inception to August 31, 2014.

Results: A total of 56 articles were included in this review. More than $80 \%$ of the studies were conducted in high-income countries. Most studies had undertaken a retrospective- and prevalence-based study design. The bottom-up approach was commonly employed to determine cost, while human capital method was used for indirect cost estimation. Database and literature were the most commonly used data sources in cost estimation in high-income countries, while chart review and interview were the main data sources in low and middle-income countries. Annual costs for the schizophrenia population in the country ranged from US\$94 million to US $\$ 102$ billion. Indirect costs contributed to $50 \%-85 \%$ of the total costs associated with schizophrenia. The economic burden of schizophrenia was estimated to range from $0.02 \%$ to $1.65 \%$ of the gross domestic product.

Conclusion: The enormous economic burden in schizophrenia is suggestive of the inadequate provision of health care services to these patients. An informed decision is achievable with the increasing recognition among public and policymakers that schizophrenia is burdensome. This results in better resource allocation and the development of policy-oriented research for this highly disabling yet under-recognized mental health disease.

Keywords: schizophrenia, economic burden, cost of illness, systematic review

\section{Introduction}

Schizophrenia is ranked among the top 25 leading causes of disability worldwide in 2013. ${ }^{1}$ Despite its low lifetime prevalence (median 4.0 per 1,000 persons ${ }^{2}$ ) and point prevalence range from 2.6 to 6.7 per $1,000,{ }^{3,4}$ health, social, and economic burden related to schizophrenia has been tremendous, not only for patients but also for families, other caregivers, and the wider society. The World Health Organization estimated that direct costs of schizophrenia in Western countries range from $1.6 \%$ to $2.6 \%$ of total health care expenditures, which in turn account for between $7 \%$ and $12 \%$ of the gross national product (GNP). ${ }^{5}$ In the US, the economic burden of schizophrenia is found to be more than US\$60 billion per year. ${ }^{6}$ Albeit the increasing evidence base, this multifaceted burden of schizophrenia remains underestimated. ${ }^{7}$ The substantial cc) ${ }_{\mathrm{BY}} \mathrm{NC}$ and incorporate the Creative Commons Atribution - Non Commercial (unported, v3.0) License (http:///creativecommons.org/licenses/by-nc/3.0/). By accessing the work you hereby accept the Terms. Non-commercial uses of the work are permitted without any further permission from Dove Medical Press Limited, provided the work is properly attributed. For permission for commercial use of this work, please see paragraphs 4.2 and 5 of our Terms (https://www.dovepress.com/terms.php). 
burden imposed by schizophrenia has been linked to the early onset of the disease and its incurable nature with persisting symptoms. ${ }^{8}$ Societies and communities find it increasingly difficult to offer support to schizophrenia patients through family and social bonds. ${ }^{9}$

With productivity losses as the largest component of the overall societal cost of schizophrenia, ${ }^{10}$ an economic burden study which often incorporates both direct and indirect costs serves as a useful source. Economic burden studies have primarily been employed to advise policymakers on resources allocation. ${ }^{11}$ Economic burden studies, however, vary due to methodology differences and costs included. These include study settings, data sources, epidemiological approaches taken (eg, prevalence- or incidence-based), cost determination method (eg, top-down, bottom-up, or a combination of both), time frame of costs, and perspective (ie, societal or payer), all of which are important factors having substantial impact on the outcomes.

Previous literature review studies were focused on summarizing direct costs associated with schizophrenia. ${ }^{12,13}$ There has been a lack of emphasis on methodology details and indirect costs estimation, which prompts the need for a more comprehensive and updated review. This study aims to systematically identify studies focusing on the economic burden of schizophrenia, describe methods and data sources, and summarize the findings of the economic burden of schizophrenia.

\section{Methods}

\section{Search strategy and data sources}

A systematic review was performed for economic burden studies in schizophrenia using four electronic databases Medline, EMBASE, PsycINFO, and EconLit. The search strategy was based on a broad combined search string "burden OR economic* OR cost* OR "cost of illness" OR resource OR expenditure" AND schizophrenia in abstract or title fields to retrieve potentially relevant publications from inception to August 31, 2014. Search strategies were limited to English and humans only.

\section{Study selection}

All identified studies were screened for relevance based on the predefined inclusion criteria. The inclusion criteria were an original research that: 1) reported cost of illness, economic burden, health care expenditure, or resource utilization for schizophrenia and 2) provided information on data sources. Studies on economic evaluation of drug or other treatment, and study population referring to a specific subgroup of schizophrenia patients only were excluded from the analysis.
Two reviewers (HYC, SLT) independently screened the identified studies based on the title and abstract using the aforementioned inclusion criteria. In case of disagreement, this was resolved by discussion between the two reviewers. Thereafter, the full-text of all potentially relevant studies was reviewed. A flow chart that illustrates the selection process is shown in Figure 1.

\section{Quality assessment}

Quality assessment is generally a crucial component of a systematic review. ${ }^{14}$ However, our review is focused mainly on describing the diversity of the methodology used in economic burden studies. Therefore, quality assessment is not relevant for our review.

\section{Data extraction}

A standardized data extraction form was used to extract data of all eligible studies. The data were extracted by HYC or SLT. In case of doubt, there was a consultation process to base the extraction upon consensus. Where possible, country, perspective, currency, pricing year, study design and approach, cost estimation methods, setting, study period/ duration, sample size, cost components, data sources, and cost estimates were defined precisely.

For costs comparison across studies, the cost estimates were converted to 2013 US dollars, based on country-specific consumer price indices ${ }^{15}$ and exchange rate. ${ }^{16}$ If the year of the cost data was not reported, it was assumed to be the publication year of the article. Furthermore, the total cost estimates in term of gross domestic product (GDP) or GNP were extracted as originally published. To facilitate further comparisons across studies in terms of the magnitude of the total estimates relative to the GDP, the total cost as percentage of GDP 2013 of the country ${ }^{15}$ was estimated.

\section{Methodological and costing approach}

The study design was classified as retrospective, prospective, cross-sectional, or modeling-based; subsequently, the approach undertaken either as prevalence- or incidencebased was defined. Prevalence-based studies estimate the costs of all disease cases (new as well as pre-existing) in a given year. ${ }^{17}$ They include medical care costs and morbidity costs of schizophrenia within the study year. ${ }^{18}$ Incidencebased studies, on the other hand, estimate the lifetime costs of a disease from its onset to its termination, which include the discounted morbidity and mortality costs for the incident cohort, usually calculated based on the year when schizophrenia first appeared. ${ }^{18}$ 


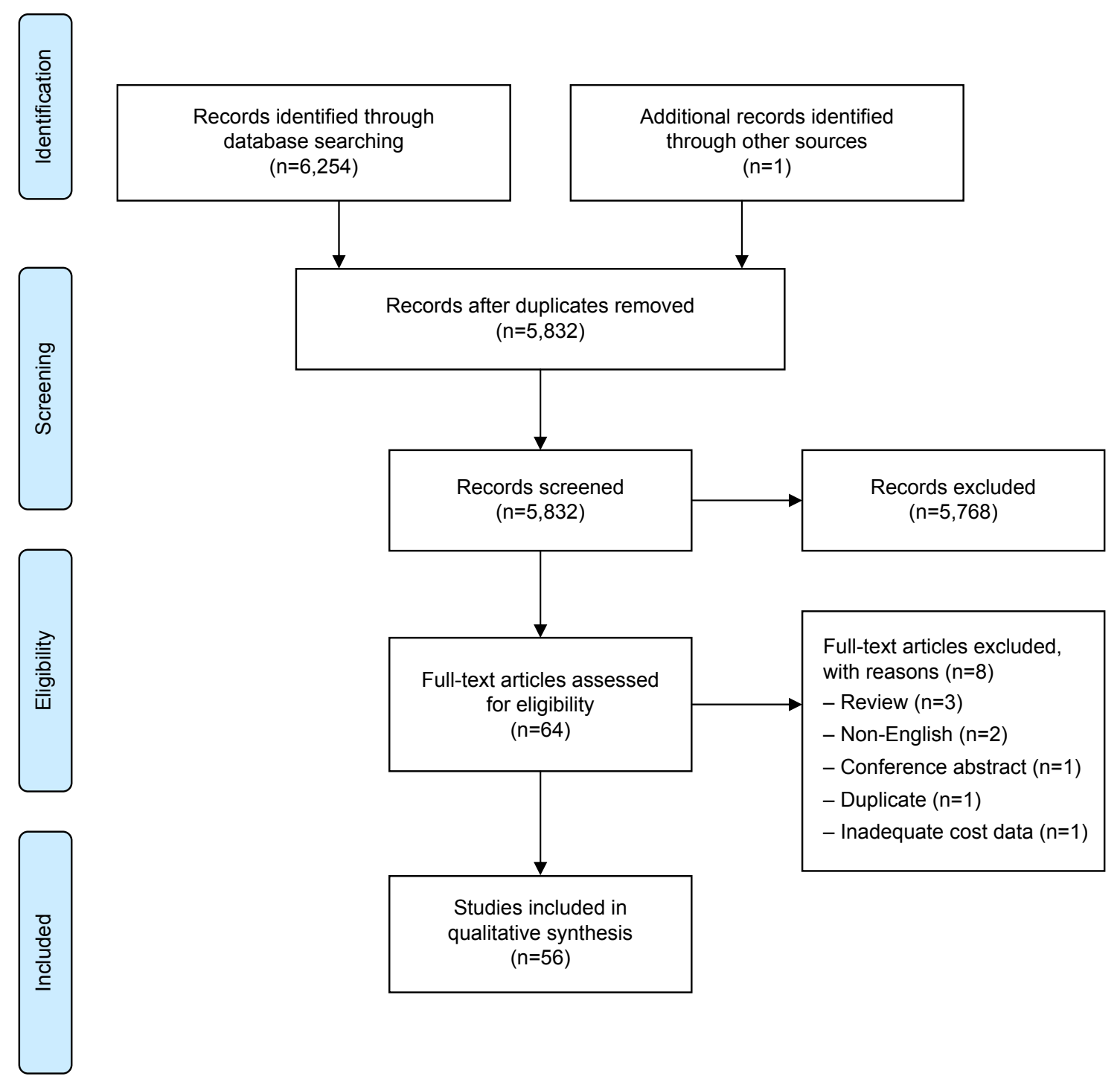

Figure I Flow diagram of the selection process to identify studies to be included.

To quantify the resources used, approaches commonly used are the top-down and bottom-up. The top-down approach estimates economic costs by using aggregate data on mortality, morbidity, hospital admissions, general practice consultations, disease-related costs, and other health-related indicators. ${ }^{18}$ Generally, this information is collected from national health care statistics, patient registers, and so on. ${ }^{18}$ The bottom-up approach calculates the resources utilization and productivity loss at the level of patient or individual. ${ }^{18,19}$ The mean per-person costs are usually then extrapolated to the whole population with relevant epidemiological data. ${ }^{18}$

\section{Cost components and data sources}

Broadly, the economic burden of schizophrenia can be reported as direct (medical and nonmedical), indirect costs, and intangible costs. Direct medical costs are expenditure for hospital inpatient care, physician inpatient care, physician outpatient care, emergency department visits, communitybased care, nursing home care, long-term institutional care, rehabilitation care, specialists' and other health professionals' care, diagnostic tests, prescription drugs, and medical supplies. ${ }^{20}$ Direct nonmedical costs are the costs of nonhealth care resources, such as transportation, food, and lodging incurred during health care visit,${ }^{21}$ and cost-associated social services. $^{22}$

Indirect costs are defined as productivity losses related to morbidity and premature mortality. Morbidity costs represent the monetary value of productivity loss due to absenteeism or sick leave (forgone work productivity), presenteeism (decreased work productivity), unemployment, permanent disability, and early retirement for patients, family members, or caregivers. ${ }^{20,23-26}$ On the other hand, mortality cost 
is defined as the monetary value of lost production due to the premature death of the patient. ${ }^{26}$ In addition, costs associated with other consequences such as incarceration are included. ${ }^{27}$

The third category of costs is referred to as intangible costs. These relate to the deterioration in quality of life to patients, families, and friends due to other factors, such as pain or suffering. ${ }^{21}$ These costs are extremely difficult to quantify, and therefore are often omitted from economic studies. ${ }^{28}$

Data sources were further classified into four major groups - database, chart, interview, and literature. Database is defined as a collection of health data in the form of: 1) population, household, and health survey; 2) surveillance data, including disease-specific registries, census, and national health accounts; ${ }^{15}$ and 3 ) electronic medical records, administrative, and claims database. Chart includes patient medical record and hospital record. Interview involves patient, caregiver, or health care provider/expert using structured/ standardized questionnaire. Literature includes published or unpublished sources and governmental report/document.

\section{Results}

\section{Study selection}

The search strategy yielded 6,255 articles, of which 423 duplicates were removed. Of the remaining 5,832 articles, only 64 met the inclusion criteria and were retrieved to be reviewed in full-text. During the full-text screening, a further eight articles were excluded due to review paper $(n=3)$, non-English publication $(n=2)$, conference abstract $(n=1)$, duplicate $(n=1)$, and inadequate information on data sources $(n=1)$. This resulted in a total of 56 relevant articles that were included in this review.

\section{General methodological characteristics}

The methodological characteristics of the included articles are summarized in Table 1. These studies were conducted for 24 countries covering four regions (25 in Europe, ${ }^{29-53} 16$ in America, ${ }^{10,54-68} 13$ in Asia Pacific, ${ }^{11,69-80}$ and 2 in Africa ${ }^{81,82}$ ). More than two-third of the studies (48/56, 86\%) were conducted in high-income countries (HIC), for example, the US $(n=13)$, Spain $(n=6)$, Germany $(n=5)$, the UK $(n=5)$, Sweden $(n=4)$, and Australia $(n=4)$.

Of the included studies, it was found that 24 studies ${ }^{10,11,31-33,36,39,43,44,52,53,55,57-61,63,65,67,68,73,77,79}$ were undertaken at the national level. Over half of the studies $(30 / 56,54 \%)$ were conducted in selected health care institutions, ${ }^{30,38,47,69,71}$, ${ }^{74-76,78,81,82}$ one or several provinces/states/counties, ${ }^{29,37,45,48,50,}$ $54,56,62,64,66,70,72$ specific health care program for schizophrenia patients, ${ }^{34,35,42,46,49,80}$ and an insurance scheme, ${ }^{51}$ while it was not reported in two studies. ${ }^{40,41}$

Less than half of studies $(23 / 56,41 \%)$ explicitly stated the perspective undertaken. The societal perspective was the most commonly employed $(n=16)$, followed by payer perspective $(\mathrm{n}=11)$.

Furthermore, most studies undertook a retrospective $(n=24)$ and prevalence-based $(\mathrm{n}=53)$ study design. Only four studies employed an incidence-based approach where two adapted discrete event modeling ${ }^{36}$ and Markov modeling, ${ }^{79}$ respectively. It is noted that Davies and Drummond ${ }^{31}$ adopted both prevalence- and incidence-based design. Only three studies estimated the lifetime costs of schizophrenia using incidence-based approach ${ }^{31,79}$ and prevalence-based approach, ${ }^{65}$ while the remaining studies presented the burden measurement as total cost and/ or average cost per patient over a specific time period.

Generally, the most commonly used method to determine costs was bottom-up $(n=37)$, followed by top-down $(n=12)$, and a combination of both methods $(n=7)$. Among 19 studies that adapted the top-down method, ${ }^{10,11,31,32,36-39}$, $43,48,52,53,56,59,60,65,72,73,7716$ were conducted using prevalencebased approach at the national level. It is noted that all 16 studies were conducted in HIC - Japan, South Korea, Taiwan, France, Ireland, the Netherlands, Spain, Sweden, UK, Canada, Puerto Rico, and the US.

\section{Overall description of cost components and data sources for cost estimation}

Among all included studies, 56 captured direct medical costs, 28 direct nonmedical costs, and 32 indirect costs. Only one study attempted to quantify intangible cost. ${ }^{41}$ Over a third of the studies $(21 / 56,38 \%)$ investigated direct medical, direct nonmedical, and indirect costs of schizophrenia.

An overview of the cost components included and data sources used in the estimation of direct medical, direct nonmedical, and indirect cost among the studies is presented in Tables 2-4. All cost components and data sources used in each study are summarized in the Supplementary table.

\section{Direct medical costs}

For the estimation of direct medical costs, the majority of the studies, asides from two studies, ${ }^{65,72}$ included costs associated with hospitalization $(n=45)$, pharmacy $(n=45)$, outpatient care $(n=33)$, or home- and community-based care $(n=31)$.

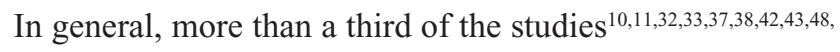
$51,52,54-64,66-68,73,80$ estimated the utilization data of direct medical cost using database $(27 / 56,48 \%)$, interview $(n=20)$, literature $(n=17)$, and chart $(n=12)$ as the data source. 


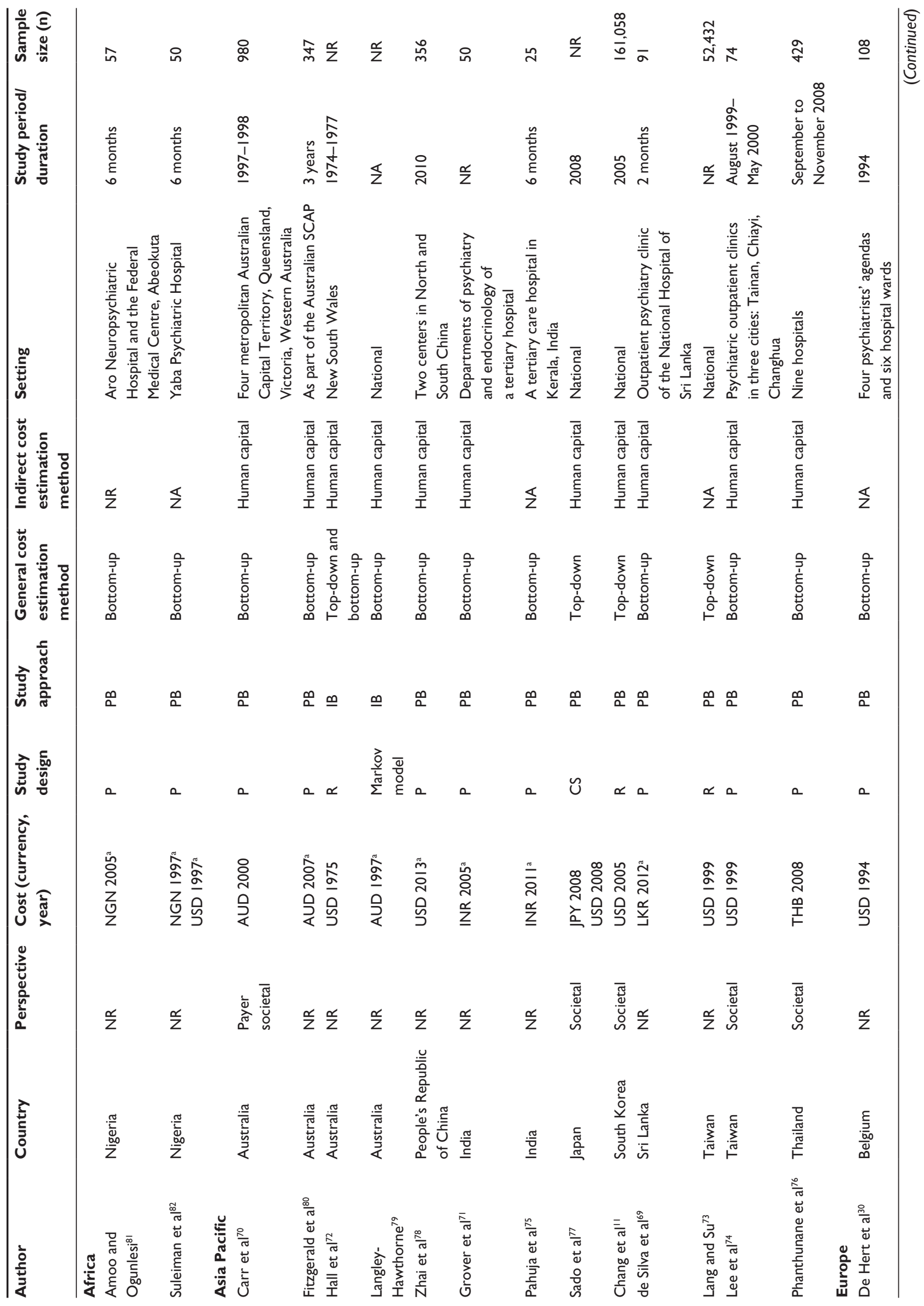




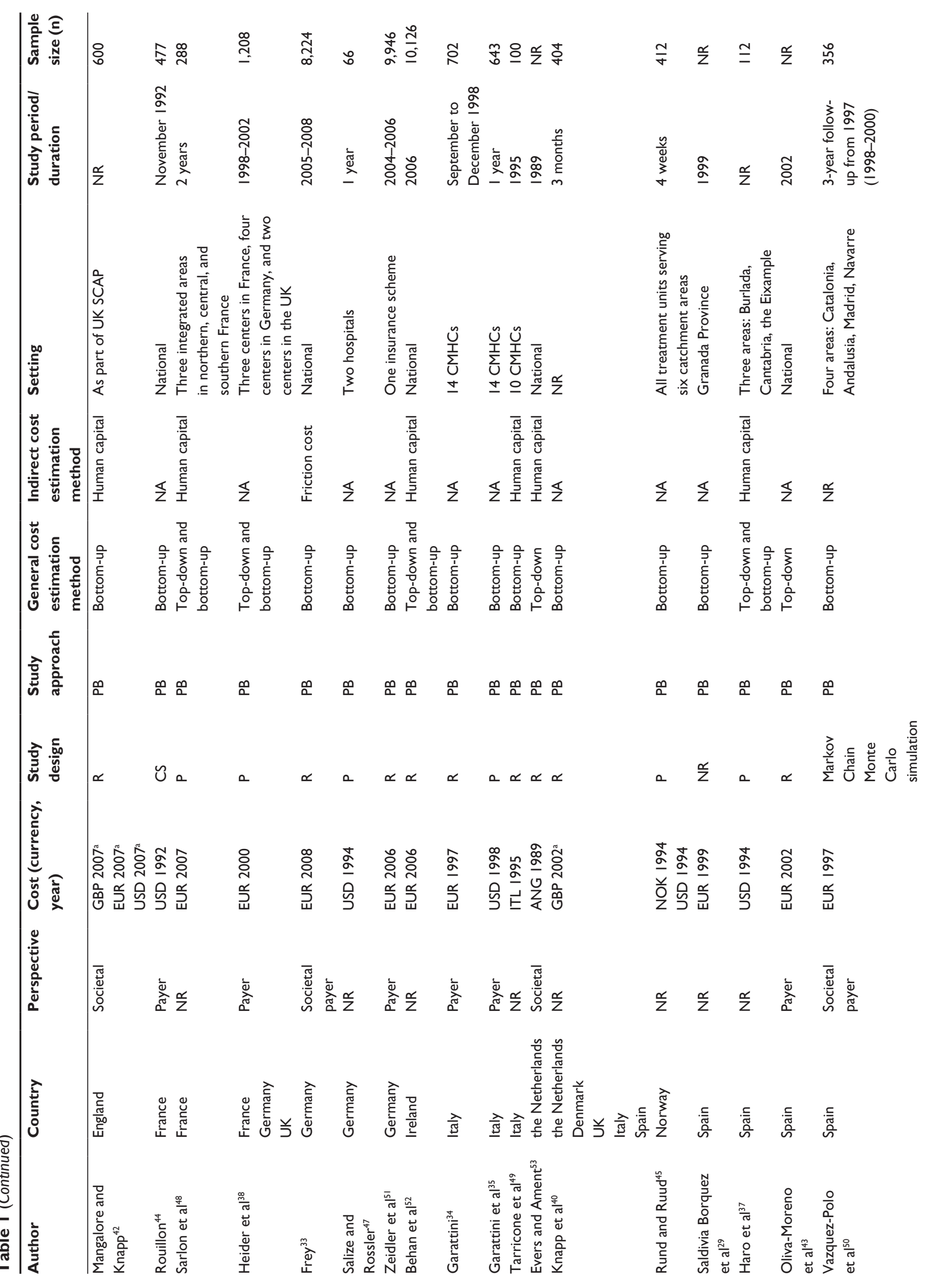




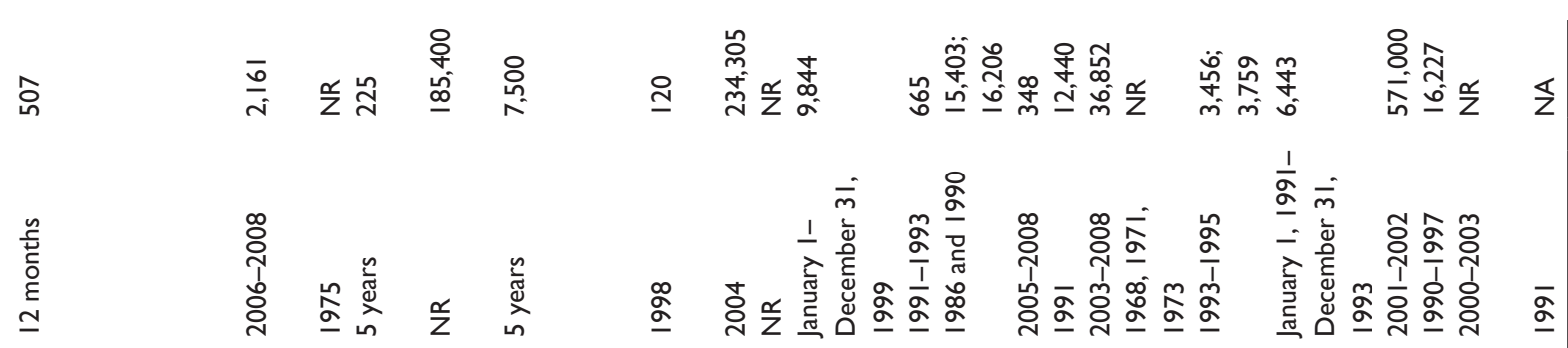

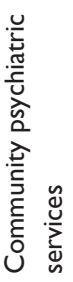

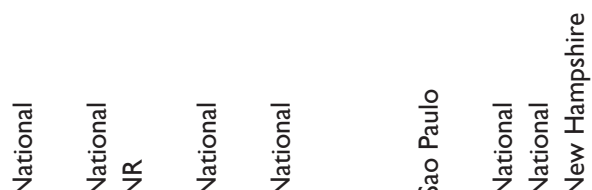

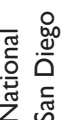

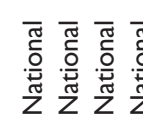

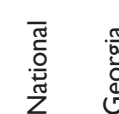

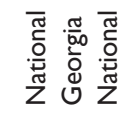

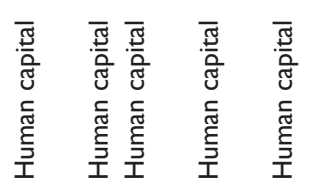

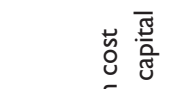

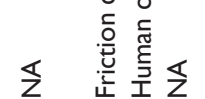

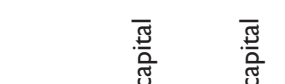

$\S$

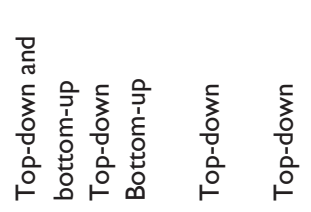

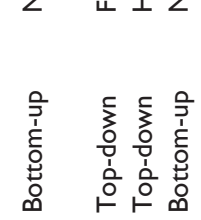

$\S \longleftarrow$

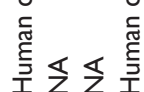

$\varangle$

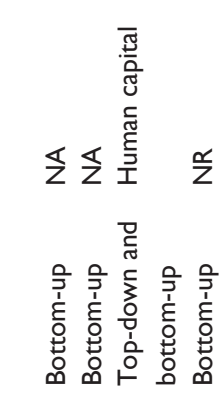

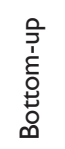

(19)

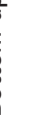

๓

๓ำ ำํำ

๓ $๓ ๓ \oplus$
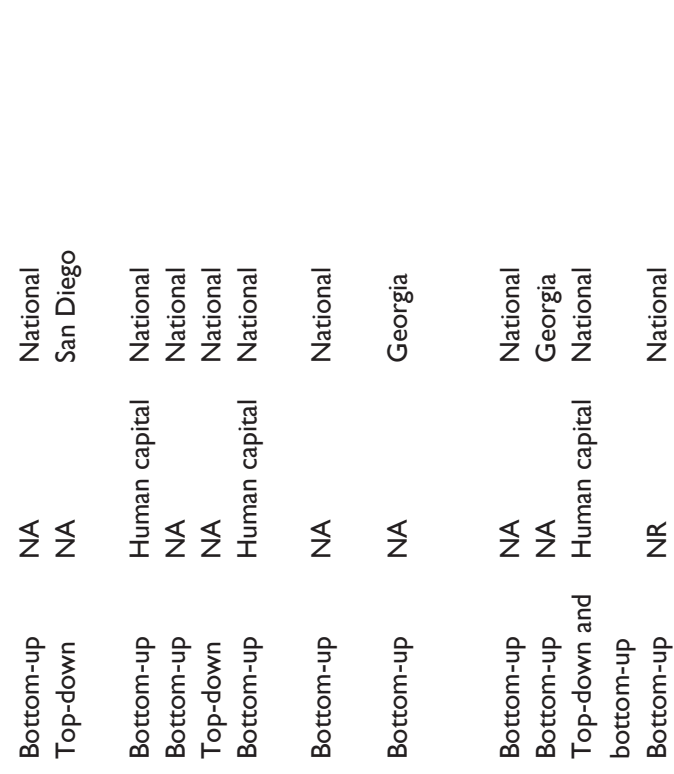

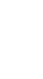

$a$

$\propto$ 品

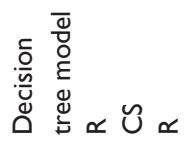

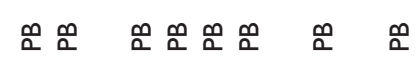

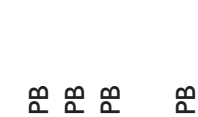

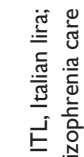

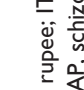

要要

空总

离

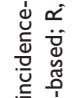

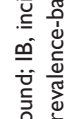

흥 흠

产

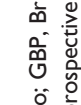

年高

를

을.

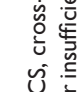

这

내웜

造

的恼

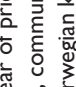

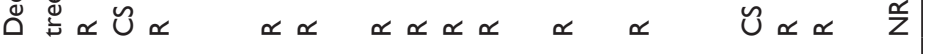

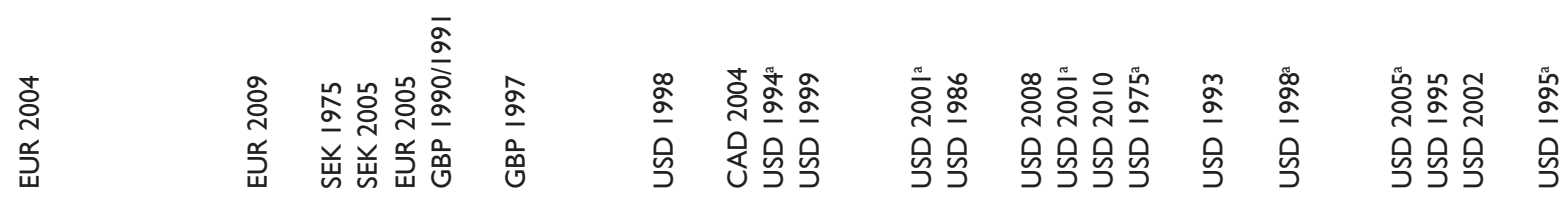

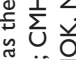

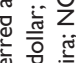

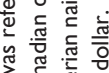

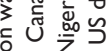

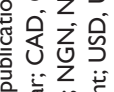

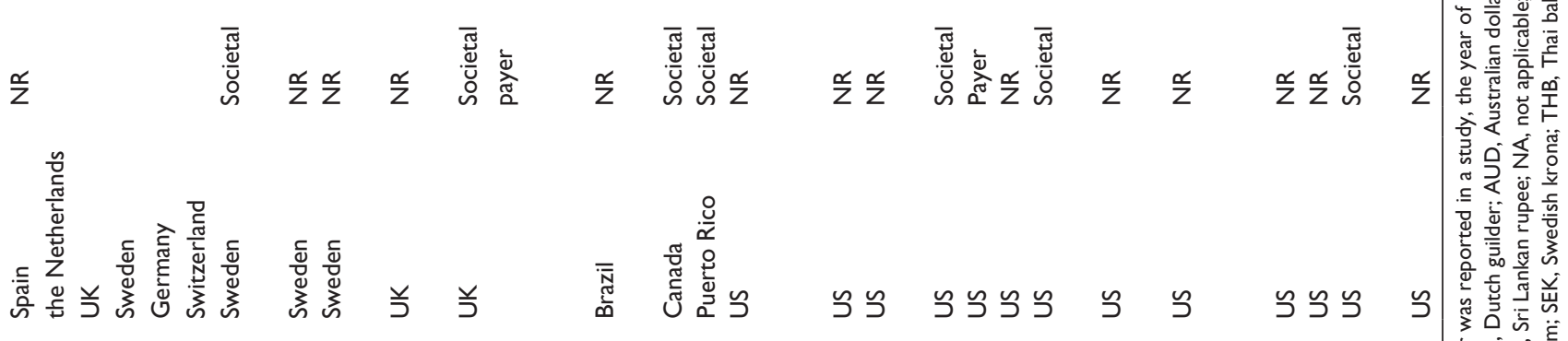

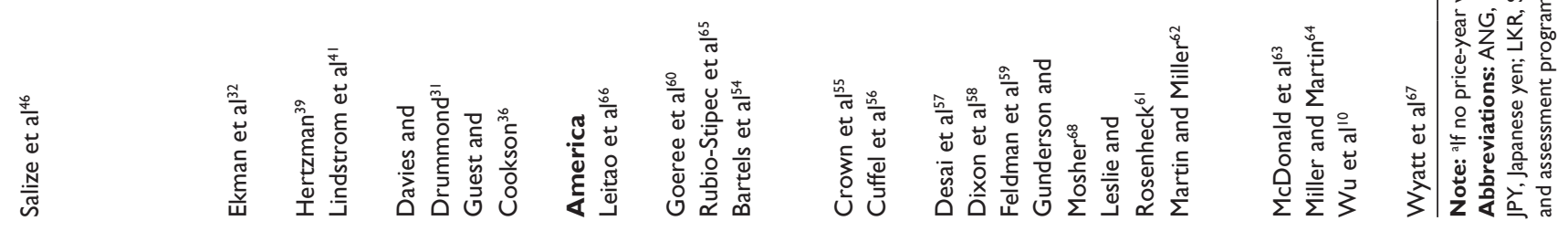




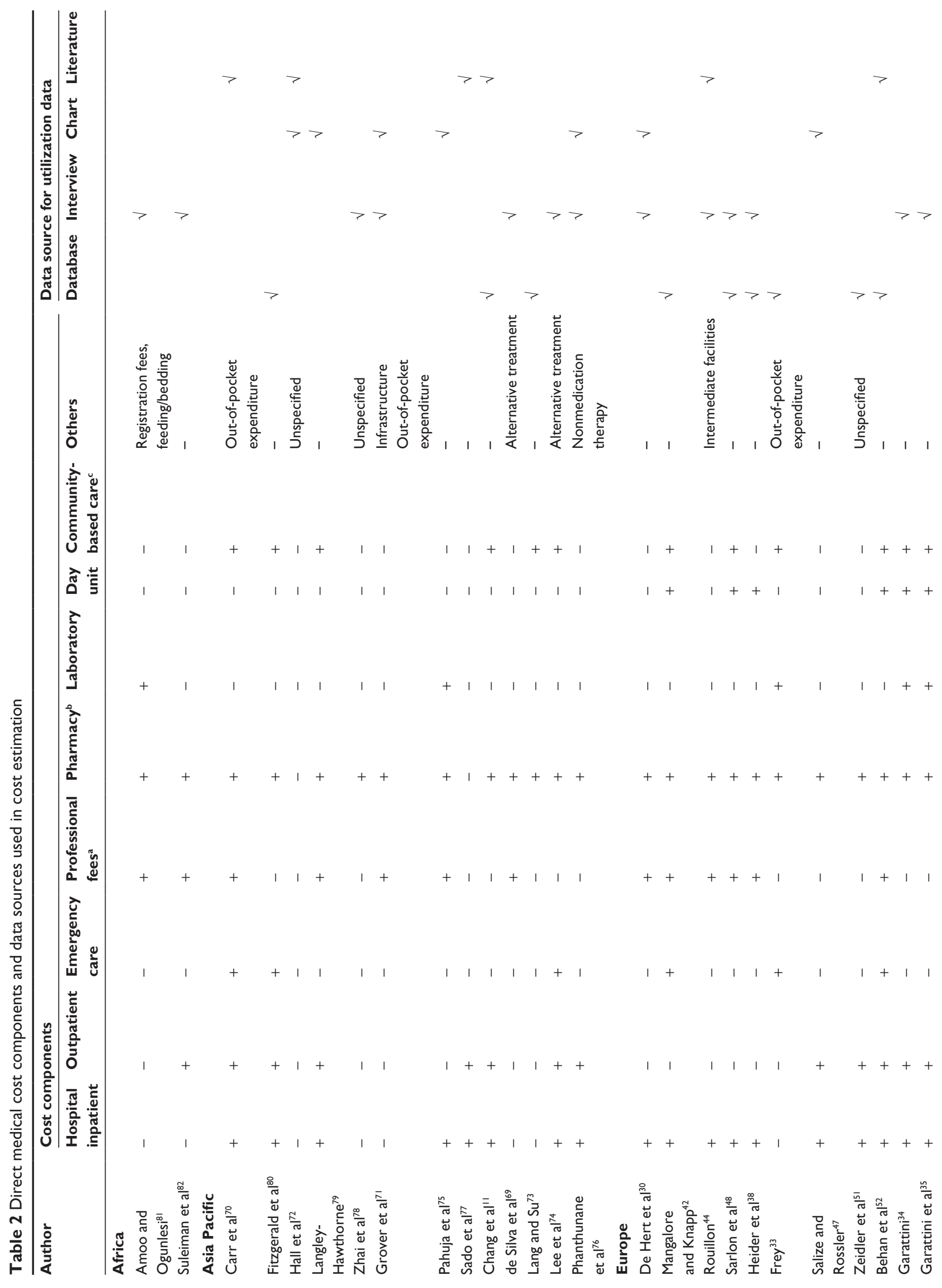




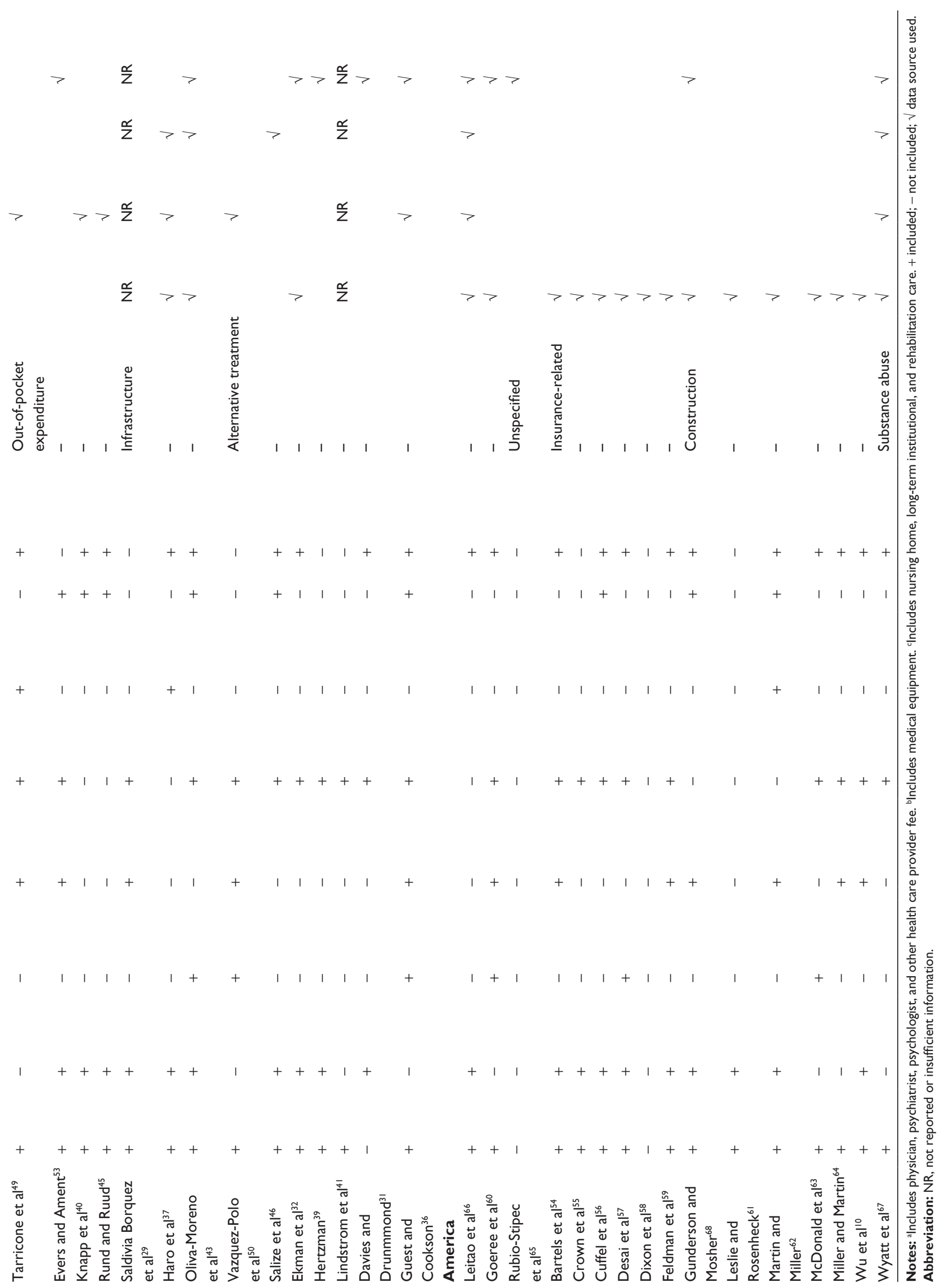


Table 3 Direct nonmedical cost components and data sources used in cost estimation

\begin{tabular}{|c|c|c|c|c|c|c|c|c|c|}
\hline \multirow[t]{2}{*}{ Author } & \multicolumn{5}{|c|}{ Cost component } & \multicolumn{4}{|c|}{ Data sources for utilization data } \\
\hline & $\begin{array}{l}\text { Homeless } \\
\text { shelter }\end{array}$ & $\begin{array}{l}\text { Social servicel } \\
\text { voluntary and } \\
\text { NGO sector }\end{array}$ & $\begin{array}{l}\text { Travel, } \\
\text { food, and } \\
\text { lodging }\end{array}$ & $\begin{array}{l}\text { Suicide- } \\
\text { related }\end{array}$ & Others & Database & Interview & Chart & Literature \\
\hline \multicolumn{10}{|l|}{ Africa } \\
\hline Amoo and Ogunlesi ${ }^{81}$ & - & - & + & - & $\begin{array}{l}\text { Pocket money for } \\
\text { patients and nurses }\end{array}$ & & $\sqrt{ }$ & & \\
\hline Suleiman et $\mathrm{a}^{82}$ & - & - & + & - & - & & $\sqrt{ }$ & & \\
\hline \multicolumn{10}{|l|}{ Asia Pacific } \\
\hline Carr et $\mathrm{a}^{70}$ & + & + & - & - & - & & & & $\sqrt{ }$ \\
\hline Langley-Hawthorne ${ }^{79}$ & + & - & - & - & - & & & & $\sqrt{ }$ \\
\hline Zhai et $\mathrm{al}^{78}$ & - & - & - & - & Unspecified & & $\sqrt{ }$ & & \\
\hline Grover et $\mathrm{al}^{71}$ & - & - & + & - & - & & $\sqrt{ }$ & & \\
\hline Sado et $\mathrm{a}^{77}$ & - & + & - & - & - & & & & $\sqrt{ }$ \\
\hline Chang et al" & + & - & + & - & - & & & & $\sqrt{ }$ \\
\hline de Silva et $a^{69}$ & - & - & + & - & - & & $\sqrt{ }$ & & \\
\hline Lee et $\mathrm{al}^{74}$ & + & + & + & - & $\begin{array}{l}\text { Community } \\
\text { resources }\end{array}$ & & $\sqrt{ }$ & & \\
\hline Phanthunane et $\mathrm{al}^{76}$ & - & - & + & - & - & & $\sqrt{ }$ & & \\
\hline \multicolumn{10}{|l|}{ Europe } \\
\hline De Hert et $\mathrm{al}^{30}$ & + & - & - & - & - & & $\sqrt{ }$ & & \\
\hline Mangalore and Knapp $\mathrm{p}^{42}$ & + & + & - & - & - & $\sqrt{ }$ & & & $\sqrt{ }$ \\
\hline Rouillon ${ }^{44}$ & - & + & - & - & - & & $\sqrt{ }$ & & $\sqrt{ }$ \\
\hline Frey ${ }^{33}$ & - & - & + & - & $\begin{array}{l}\text { Housekeeping, } \\
\text { administrative, } \\
\text { hospital investments }\end{array}$ & $\sqrt{ }$ & & & \\
\hline Salize and Rossler ${ }^{47}$ & + & - & - & - & - & & & $\sqrt{ }$ & \\
\hline Behan et $\mathrm{a}^{52}$ & + & + & - & - & - & & & & $\sqrt{ }$ \\
\hline Evers and Ament ${ }^{53}$ & + & - & - & - & - & & & & $\sqrt{ }$ \\
\hline Knapp et $\mathrm{a}^{40}$ & + & - & - & - & - & & $\sqrt{ }$ & & \\
\hline Vazquez-Polo et $\mathrm{a}^{50}$ & + & + & - & - & - & & $\sqrt{ }$ & & \\
\hline Salize et a $\left.\right|^{46}$ & + & - & - & - & - & & & $\sqrt{ }$ & \\
\hline Lindstrom et $\mathrm{al}^{41}$ & + & - & - & - & - & NR & NR & NR & NR \\
\hline Guest and Cookson ${ }^{36}$ & + & - & - & - & - & & $\sqrt{ }$ & & $\sqrt{ }$ \\
\hline \multicolumn{10}{|l|}{ America } \\
\hline Goeree et $\mathrm{a}^{60}$ & + & - & - & + & - & & & & $\sqrt{ }$ \\
\hline Gunderson and Mosher ${ }^{68}$ & - & - & - & - & Research & & & & $\sqrt{ }$ \\
\hline Martin and Miller ${ }^{62}$ & - & - & + & - & - & $\sqrt{ }$ & & & \\
\hline Wu et a ${ }^{10}$ & + & - & - & - & $\begin{array}{l}\text { Research and } \\
\text { training }\end{array}$ & & & & $\sqrt{ }$ \\
\hline Wyatt et $\mathrm{a}^{67}$ & + & - & - & + & - & & $\sqrt{ }$ & & $\sqrt{ }$ \\
\hline
\end{tabular}

Notes: + included; - not included; $\sqrt{ }$ data source used.

Abbreviations: NGO, non-governmental organization; NR, not reported or insufficient information.

In 48 studies $^{10,11,29-59,60-65,67,68,70,72-74,77,79,80}$ conducted in HIC, database $(n=26)$ and literature $(n=16)$ were most commonly applied as the data source. Claims database was used as the primary data source in ten studies. In contrast, from the eight studies conducted in low- and middle-income countries (LMIC), interview $(n=7)$ was the most commonly used data source for direct medical cost estimation, followed by chart $(n=4)$.

\section{Direct nonmedical costs}

A total of 28 studies $^{10,11,30,33,36,40-42,44,46,47,50,52,53,60,62,67-71,74,76-79,81,82}$ estimated the direct nonmedical cost in which homeless shelter $(n=18)$, travel, food, and lodging expenses $(n=9)$, social care $(n=7)$, and suicide-related $(n=2)$ costs were measured. Data sources used to estimate utilization data of these costs were interview $(n=12)$, literature $(n=11)$, database $(n=4)$, and chart $(n=2)$.

In 28 studies that estimated direct nonmedical costs, literature $(n=12)$ and interview $(n=8)$ were the main data sources used in HIC, while interview $(\mathrm{n}=6)$ was used in LMIC.

\section{Indirect costs}

In 32 studies that included indirect cost estimates, the human capital approach was used in 27 studies. Friction cost 


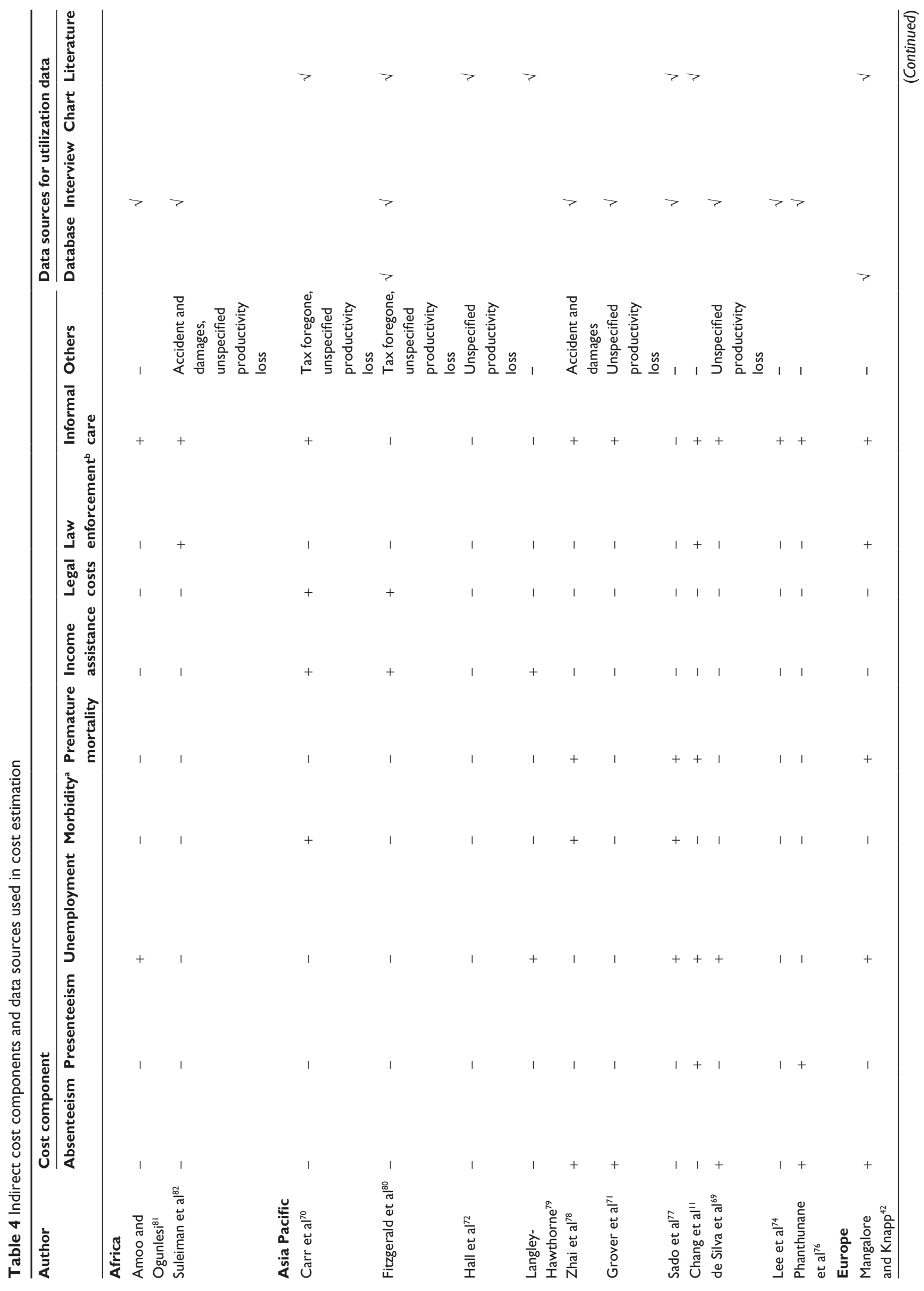




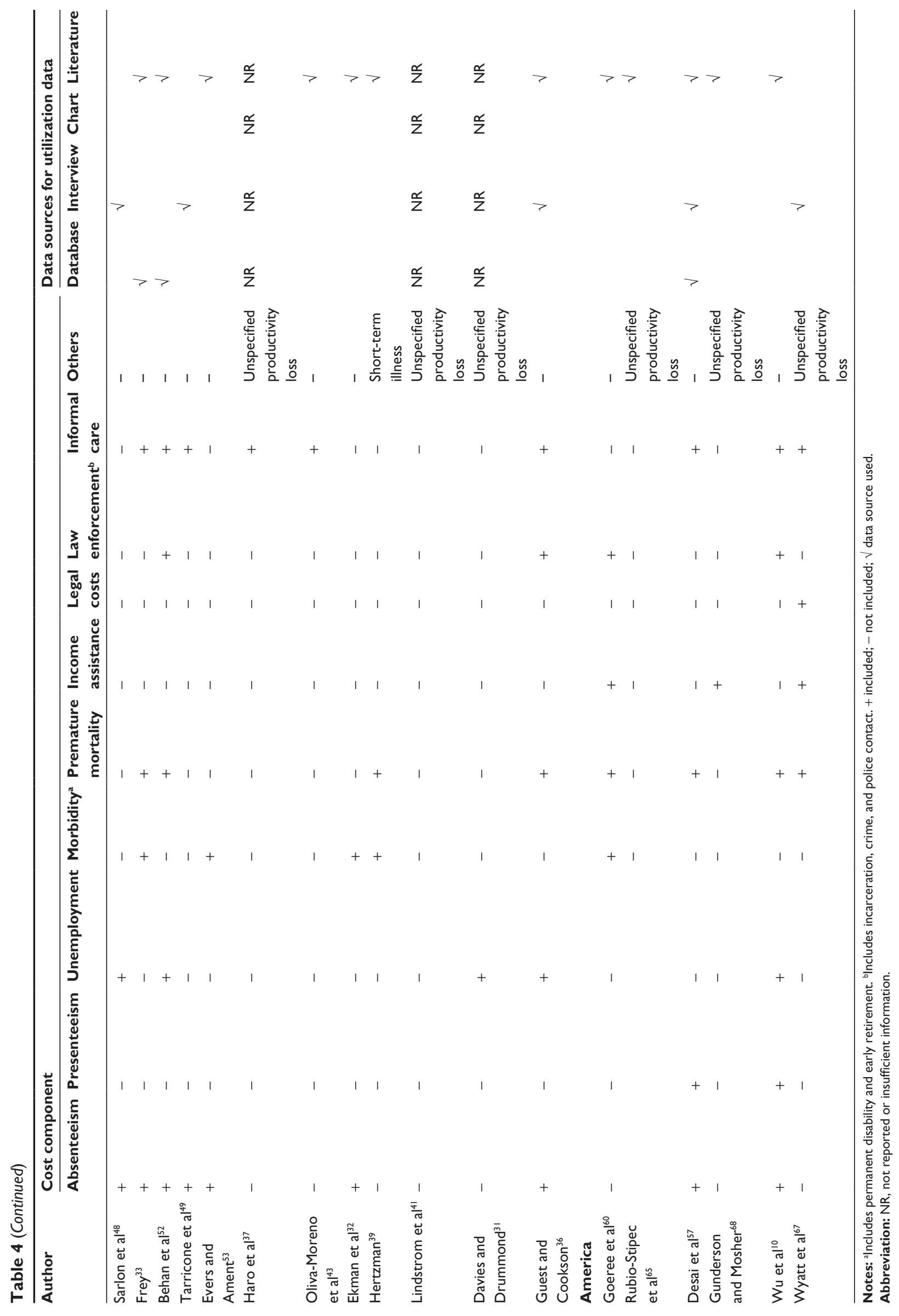


approach was used in two studies in Germany and Canada. ${ }^{33,60}$

To estimate indirect costs, more than half (19/32, 59\%) took into account informal care cost. Furthermore, other main components calculated were productivity loss associated with absenteeism $(n=14)$, premature mortality $(n=12)$, and unemployment $(n=11)$. These indirect costs were estimated mainly based on literature $(n=19)$, interview $(n=15)$, and database $(n=5)$ as their data sources.

Literature $(n=19)$ was used as the main data source in studies from HIC, while it was interview $(n=6)$ in studies from LMIC. In addition, it is found that published mean wage was used as the unit cost in the estimation of productivity loss in all studies from HIC, while reported individual wage obtained from the interview performed was used in three studies from LMIC. ${ }^{69,71,76}$

\section{Cost estimates of schizophrenia}

Cost estimates from 15 national studies that investigated both direct and indirect costs are presented in Table 5 in terms of cost in US dollars in 2013, and the share of the direct medical cost, direct nonmedical cost, and indirect cost. The total cost estimates reported varied significantly where annual costs for the schizophrenia population in the country reported ranged from US\$94 million in Puerto Rico ${ }^{65}$ to US\$102,396 million in the US. ${ }^{67}$ Furthermore, there was a substantial difference in annual cost estimates in studies conducted in the same country where US\$123 million ${ }^{32}$ to US\$9,134 million ${ }^{39}$ in Sweden and US\$25,452 million $^{57}$ to US\$102,396 million ${ }^{67}$ in the US was found.

Notably, indirect costs contributed to $50 \%-85 \%$ of the overall costs associated with schizophrenia in 12 national studies; ${ }^{10,11,32,36,39,52,57,60,65,67,68,77}$ only three studies reported otherwise. ${ }^{33,43,53}$ Similar findings were noted in six studies from LMIC with direct and indirect cost estimates; the contribution of indirect costs to total annual costs is demonstrated to range from $63 \%$ to $82 \%$ as compared to direct costs, ${ }^{69,71,76,78}$ except for two studies from Nigeria. ${ }^{81,82}$ The cost estimates in LMIC are shown in Table 6.

Only three studies reported the total annual costs incurred by schizophrenia as percentage of $\mathrm{GDP}^{70,74}$ or $\mathrm{GNP}^{68}$ in the country. However, results varied significantly where it was $0.23 \%-0.36 \%$ GDP in Australia, 5.46\% GDP in Taiwan, and

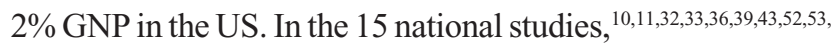
$57,60,65,67,68,77$ the total cost as \% GDP in the country estimated was found to range from $0.02 \%$ in $\mathrm{UK}^{36}$ to $1.65 \%$ in Sweden. ${ }^{39}$

\section{Discussion}

This is the first systematic review summarizing the methodologies used in estimating economic burden of schizophrenia globally. We focused on describing the methodology adopted and its practice. Trends in adopting certain methodological

Table 5 Annual cost estimate of direct and indirect costs and total cost as \% of GDP (USD 20I3) in national studies

\begin{tabular}{|c|c|c|c|c|c|c|c|c|c|}
\hline \multirow[t]{2}{*}{ Author } & \multirow[t]{2}{*}{ Country } & \multicolumn{4}{|c|}{$\begin{array}{l}\text { Cost estimates } \\
\text { (USD } 2013, \text { millions) }\end{array}$} & \multicolumn{3}{|c|}{$\begin{array}{l}\text { Cost contribution to total } \\
\text { cost }(\%)\end{array}$} & \multirow{2}{*}{$\begin{array}{l}\text { Total cost } \\
\text { as \% GDP } \\
\text { (USD 2013) }\end{array}$} \\
\hline & & $\begin{array}{l}\text { Direct } \\
\text { medical } \\
\text { cost }\end{array}$ & $\begin{array}{l}\text { Direct } \\
\text { nonmedical } \\
\text { cost }\end{array}$ & $\begin{array}{l}\text { Indirect } \\
\text { cost }\end{array}$ & Total & $\begin{array}{l}\text { Direct } \\
\text { medical } \\
\text { cost }\end{array}$ & $\begin{array}{l}\text { Direct } \\
\text { nonmedical } \\
\text { cost }\end{array}$ & $\begin{array}{l}\text { Indirect } \\
\text { cost }\end{array}$ & \\
\hline \multicolumn{10}{|l|}{ Asia Pacific } \\
\hline Sado et $\mathrm{al}^{77}$ & Japan & 7,247 & 33 & 18,950 & 26,230 & 28 & $<0.1$ & 72 & 0.52 \\
\hline Chang et al'" & South Korea & 519 & 36 & 3,204 & 3,759 & 14 & 1 & 85 & 0.31 \\
\hline \multicolumn{10}{|l|}{ Europe } \\
\hline Behan et $\mathrm{al}^{52}$ & Ireland & 172 & 13 & 488 & 673 & 25 & 2 & 73 & 0.30 \\
\hline Frey ${ }^{33}$ & Germany & 10,635 & 354 & 8,978 & 19,967 & 53 & 2 & 45 & 0.56 \\
\hline Evers and Ament ${ }^{53}$ & the Netherlands & 774 & 50 & 70 & 894 & 87 & 6 & 8 & 0.11 \\
\hline Olivia-Moreno et $\mathrm{al}^{43}$ & Spain & 1,882 & NA & 1,669 & 3,552 & 53 & NA & 47 & 0.26 \\
\hline Ekman et $\mathrm{al}^{32}$ & Sweden & 29 & NA & 94 & 123 & 24 & NA & 76 & 0.02 \\
\hline Hertzman ${ }^{39}$ & Sweden & 3,712 & NA & 5,422 & 9,134 & 41 & NA & 59 & 1.65 \\
\hline Guest and Cookson ${ }^{36}$ & UK & 154 & 49 & 199 & 403 & 38 & 12 & 50 & 0.02 \\
\hline \multicolumn{10}{|l|}{ America } \\
\hline Goeree et $\mathrm{al}^{60}$ & Canada & 2,111 & 102 & 5,287 & 7,500 & 28 & $<0.1$ & 72 & 0.41 \\
\hline Rubio-Stipec et al ${ }^{65}$ & Puerto Rico & 31 & NA & 63 & 94 & 33 & NA & 67 & 0.09 \\
\hline Desai et $a^{57}$ & US & 4,742 & NA & 20,710 & 25,452 & 19 & NA & 81 & 0.15 \\
\hline Wu et $\mathrm{al}^{10}$ & US & 29,279 & $12,0 \mid 4$ & $41,7 \mid 4$ & 83,007 & 35 & 14 & 50 & 0.50 \\
\hline Wyatt et $\mathrm{al}^{67}$ & US & 27,745 & 4,054 & 70,597 & 102,396 & 27 & 4 & 69 & 0.61 \\
\hline Gunderson and Mosher ${ }^{68}$ & US & 12,078 & 57 & 48,200 & 60,335 & 20 & $<0.1$ & 80 & 0.36 \\
\hline
\end{tabular}

Abbreviations: GDP, gross domestic product; NA, not applicable; USD, US dollar. 
Table 6 Annual cost estimate of direct and indirect costs in LMIC

\begin{tabular}{|c|c|c|c|c|c|c|c|c|}
\hline \multirow[t]{2}{*}{ Author } & \multirow[t]{2}{*}{ Country } & \multicolumn{4}{|c|}{ Cost estimates (USD 2013) } & \multicolumn{3}{|c|}{ Cost contribution to total cost (\%) } \\
\hline & & $\begin{array}{l}\text { Direct } \\
\text { medical } \\
\text { cost }\end{array}$ & $\begin{array}{l}\text { Direct } \\
\text { nonmedical } \\
\text { cost }\end{array}$ & $\begin{array}{l}\text { Indirect } \\
\text { cost }\end{array}$ & Total & $\begin{array}{l}\text { Direct } \\
\text { medical } \\
\text { cost }\end{array}$ & $\begin{array}{l}\text { Direct } \\
\text { nonmedical } \\
\text { cost }\end{array}$ & $\begin{array}{l}\text { Indirect } \\
\text { cost }\end{array}$ \\
\hline Amoo and Ogunlesi ${ }^{81}$ & Nigeria & $9,882^{\mathrm{a}}$ & NR & 3,604 & 13,486 & $73^{\mathrm{a}}$ & NR & 27 \\
\hline Suleiman et $\mathrm{al}^{82}$ & Nigeria & 2,951 & 80 & 430 & 3,461 & 85 & 2 & 12 \\
\hline Zhai et $\mathrm{al}^{78}$ & $\begin{array}{l}\text { People's Republic } \\
\text { of China }\end{array}$ & 257,980 & 44,237 & 515,297 & 817,514 & 32 & 5 & 63 \\
\hline Grover et $\mathrm{al}^{71}$ & India & $1,8 \mid 4$ & 718 & 4,310 & 6,842 & 27 & 10 & 63 \\
\hline de Silva et $a^{69}$ & Sri Lanka & 25,075 & 186 & III,574 & 136,834 & 18 & 0.1 & 82 \\
\hline Phanthunane et $\mathrm{al}^{76}$ & Thailand & $6,661,900$ & 521,900 & $17,613,000$ & $24,796,800$ & 27 & 2 & 7I \\
\hline
\end{tabular}

Note: ancludes direct nonmedical cost.

Abbreviations: USD, US dollar; NR, not reported or insufficient information; LMIC, low- and middle-income countries.

aspects were observed, attributed to data availability and accessibility, methodological feasibility, and practicality.

Our study revealed that the data sources used for estimating economic burden of schizophrenia were distinctively different between HIC and LMIC. We found that electronic database was the most common data source for HIC as it provided more representative cost estimates given its large sample size. This was not the case for LMIC where electronic database was less available and accessible, leading to the use of interview and chart review for data collection. Even though interview is resource-intensive, it can capture outof-pocket expenditures. We believe that the use of multiple data sources is needed to enhance comprehensiveness of cost findings since one single data source will not be able to capture all relevant costs.

Of all studies reviewed, prevalence-based approach was the most frequently used. However, for chronic illnesses such as schizophrenia, incidence-based approach is more relevant, ${ }^{83}$ by informing the lifetime costs potentially saved by averting a case of schizophrenia. Prevalence-based studies, however, could be interpreted as a snapshot of the costs incurred by schizophrenia in a year. ${ }^{83}$ Nevertheless, less data and fewer assumptions required for a prevalence-based approach enhanced its practicality. ${ }^{83}$ It is recommended for future economic burden studies to implement both study designs alongside to obtain complementary findings.

Our findings revealed indirect costs contributed most to the overall costs in economic burden studies conducted from societal perspective. Economic burden studies conducted from a narrower perspective, excluding indirect costs, consequently underestimated costs incurred by schizophrenia substantially. Unless the purpose of economic burden study is to serve as evidence for payers only, the inclusion of indirect costs is warranted to measure economic burden impacted by schizophrenia on the society. Nevertheless, the accuracy of indirect costs is subjected to the cost estimation method applied.
In estimating indirect costs, human capital method was found to be more prevalent than friction cost method in our review. In view of the theory behind both methods, friction cost method appears to yield more realistic estimates than human capital method in chronic diseases, such as schizophrenia. ${ }^{84}$ This is because long-term absences due to schizophrenia or associated mortality will be covered by a person drawn from the pool of unemployed. ${ }^{85}$ Therefore, there is a little loss to society overall. ${ }^{85}$ Often, due to its practicality and broad scope, human capital method might have been chosen. Considering the strengths and limitations of both methods, ${ }^{86}$ it is highly recommended to use both methods when conducting economic burden analysis to provide comprehensive indirect cost estimates, and thus its comparability can be enhanced.

In addition to the cost components typically captured, special cost components were captured in some studies in our review, ${ }^{10,11,30,36,40-42,46,47,49,50,52,53,60,67,70,74,78,79,82}$ namely, homeless shelter, law enforcement, and accident and damage. In a broader perspective, the prevalence of homelessness is potentially linked to social isolation, stigmatization, and caregiver burden; violent behavior associated with schizophrenia could have contributed to the costs of law enforcement and accident and damage. These special cost components were somewhat specific to schizophrenia which can have a substantial impact on the society in terms of economic and humanistic burden.$^{87}$ While not all studies in our analysis valued these cost components, we highlight its existence of this kind of special cost component and its contribution to overall economic burden of schizophrenia.

Our systematic review showed that all included studies revealed substantial economic impact associated with schizophrenia. The annual costs were estimated to be in the range of US\$94 million to US\$102 billion, which translated into $0.02 \%-5.46 \%$ of GDP. In addition, the economic burden reported in slightly less than half of the 
national studies $(7 / 15,47 \%)$ ranged between $0.30 \%$ and $0.60 \%$ GDP, consistent with those reported in Asia Pacific region. However, there were some extremely low estimates particularly in countries with tax-funded health care during the study period, namely, Sweden, the UK, and Puerto Rico. Therefore, this discrepancy was likely due to the differences in health care system, pattern of resource utilization, scope of cost components, diversity of the sampled populations, and data sources used. ${ }^{20,88}$ Nevertheless, this magnitude of economic burden demonstrated that schizophrenia has been inadequately treated which underscores the need for a comprehensive approach to controlling its impact.

This review is useful to inform health policymakers on the current status of economic burden studies in schizophrenia. In addition, this review advocates increasing the awareness of public and policymakers to recognize schizophrenia as a burdensome illness. In turn, more resources need to be allocated in treating the illness and develop new lines of policy-oriented research targeted on schizophrenia.

Our systematic review is different from previous review studies in a number of aspects. Previous review studies focused only on quantitative findings on the economic burden of schizophrenia. ${ }^{12,13}$ They did not provide a summary of the methodologies undertaken and discuss the implications of methodology on the findings. This present review provides an overall comprehensive comparison of methodologies used in economic burden studies, which could generate insightful information for future economic studies in adopting the relevant methodological approach. In addition, we performed a review using a systematic approach following the Preferred Reporting Items for Systematic Reviews and Meta-Analyses statement, which led to a better and more comprehensive summary of the overall economic burden studies in current literature.

A limitation of this systematic review is the inclusion of only English literature. It was clear that a number of literatures have been published in local languages, which are evident to be more prevalent among LMIC ${ }^{89}$ We intentionally excluded non-English literature because of our limited capacity to understand non-English language. During our exhaustive search, we identified two non-English articles which might have provided more information if we had broadened our inclusion criteria.

Our study highlighted the variety of methodological approaches in estimating the economic burden of schizophrenia. On a similar note, it is also crucial to report explicitly on cost components incorporated and their calculations. In order to improve the comparison and interpretation of the economic burden findings, we recognize and recommend the need to develop a guidance document in both the conduct and reporting of future studies for estimating the economic burden of schizophrenia.

\section{Conclusion}

Despite the wide variation in methodologies and cost components in studies reviewed, there is a general consensus which can be drawn that schizophrenia imposes a substantial economic burden on society mainly driven by high indirect costs. Understanding the magnitude of the wide-ranging economic and social burden of schizophrenia among policymakers enables informed decisions to be made by establishing health care priorities and allocating scarce resources for this highly disabling yet under-recognized mental health disease.

\section{Acknowledgment}

This research was supported by Janssen Pharmaceutical Companies Asia Pacific, Singapore.

\section{Disclosure}

A related abstract was presented in the International Society of Pharmacoeconomics and Outcomes Research (ISPOR) 6th Asia Pacific Conference and published in Value in Health. $\mathrm{NC}$ and DBCW received financial support from Janssen. $\mathrm{CFC}$ is an employee of Janssen. The authors declare no other conflicts of interest in this work.

\section{References}

1. Vos T, Barber RM, Bell B, et al. Global, regional, and national incidence, prevalence, and years lived with disability for 301 acute and chronic diseases and injuries in 188 countries, 1990-2013: a systematic analysis for the global burden of disease study 2013. Lancet. 386(9995): 743-800.

2. Saha S, Chant D, Welham J, McGrath J. A systematic review of the prevalence of schizophrenia. PLoS Med. 2005;2(5):e141.

3. World Health Organization (WHO). Mental Health: New Understanding, New Hope. Geneva: WHO; 2001.

4. Jablensky A. The 100-year epidemiology of schizophrenia. Schizophr Res. 1997;28(2-3):111-125.

5. Barbato A. Schizophrenia and Public Health. Geneva: World Health Organization; 1998.

6. Marcus SC, Olfson M. Outpatient antipsychotic treatment and inpatient costs of schizophrenia. Schizophr Bull. 2008;34(1):173-180.

7. Phanthunane P, Vos T, Whiteford H, Bertram M, Udomratn P. Schizophrenia in Thailand: prevalence and burden of disease. Popul Health Metr. 2010;8:24

8. American Psychiatric Association. Diagnostic and Statistical Manual of Mental Disorders. Washington, DC: American Psychiatric Association; 1994.

9. Brundtland GH. Mental health in the 21st century. Bull World Health Organ. 2000;78(4):411-411.

10. Wu EQ, Birnbaum HG, Shi L, et al. The economic burden of schizophrenia in the United States in 2002. J Clin Psychiatry. 2005;66: $1122-1129$. 
11. Chang SM, Cho S-J, Jeon HJ, et al. Economic burden of schizophrenia in South Korea. J Korean Med Sci. 2008;23(2):167-175.

12. Williams R, Dickson RA. Economics of schizophrenia. Can J Psychiatry. 1995;S60-S67.

13. Millier A, Shupo F, Chauhan D, Toumi M. PMH17 Economic burden in schizophrenia: a literature review. Val Health. 2012;15(7):A336.

14. PRISMA. Conceptual issues in the evolution from QUORUM to PRISMA. Available from: http://www.prisma-statement.org/ conceptual.htm. Accessed January 14, 2015.

15. International Monetary Fund. World Economic Outlook Database 2013. Washington, DC: International Monetary Fund; 2013.

16. FxTop. Currency converter. Available from: http://fxtop.com/en/ currency-converter-past.php. Accessed November 7, 2014.

17. Saha S, Gerdtham UG. Cost of illness studies on reproductive, maternal, newborn, and child health: a systematic literature review. Health Econ Rev. 2013;3(1):24.

18. Rice DP, Miller LS. The economic burden of schizophrenia: Conceptual and methodological issues, and cost estimates. In: Moscarelli M, Rupp A, Sartorius N, editors. Handbook of Mental Economics and Health Policy. Volume 1: Schizophrenia. London: Wiley; 1996: 321-334.

19. Mogyorosy Z, Smith P. The Main Methodological Issues in Costing Health Care Services: A Literature Review. York: Center for Health Economics, University of York; 2005.

20. Ng CS, Lee JY, Toh MP, Ko Y. Cost-of-illness studies of diabetes mellitus: a systematic review. Diabetes Res Clin Pract. 2014;105(2): 151-163.

21. Kleine-Budde K, Touil E, Moock J, Bramesfeld A, Kawohl W, Rossler W. Cost of illness for bipolar disorder: a systematic review of the economic burden. Bipolar Disord. 2014;16(4):337-353.

22. Wimo A, Jönsson L, Gustavsson A. Health economics aspects of dementia. Available from: http://www.alzheimer-europe.org/Research/ European-Collaboration-on-Dementia/Cost-of-dementia/Healtheconomic-aspects-of-dementia. Accessed November 4, 2015.

23. Leardini G, Salaffi F, Caporali R, Canesi B, Rovati L, Montanelli R. Direct and indirect costs of osteoarthritis of the knee. Clin Exp Rheumatol. 2004;22(6):699-706.

24. Castro DM, Dillon C, Machnicki G, Allegri RF. The economic cost of Alzheimer's disease: family or public health burden?. Dement Neuropsychol. 2010;4(4):262-267.

25. Filipovic I, Walker D, Forster F, Curry AS. Quantifying the economic burden of productivity loss in rheumatoid arthritis. Rheumatology (Oxford). 2011;50:1083-1090.

26. Dadoun S, Guillemin F, Lucier S, et al. Work productivity loss in early arthritis during the first 3 years of disease: a study from a French national multicenter cohort. Arthritis Care Res. 2014;66(9):1310-1318.

27. Modi P, Suvarna K, Cooper GJ. Images in cardiology. Descending thoracic aortic aneurysm in rheumatoid arthritis. Heart. 2000; 84(2):122

28. Cooper NJ. Economic burden of rheumatoid arthritis: a systematic review. Rheumatology (Oxford). 2000;39(1):28-33.

29. Saldivia Borquez S, Torres Gonzalez F, Cabases Hita JM. Estimation of mental health care cost units for patients with schizophrenia. Actas Esp Psiquiatr. 2005;33(5):280-285.

30. De Hert M, Thys E, Boydens J, et al. Health care expenditure on schizophrenia patients in Belgium. Schizophr Bull. 1998;24(4):519-527.

31. Davies LM, Drummond MF. Economics and schizophrenia: the real cost. Br J Psychiatry Suppl. 1994;165(25):18-21.

32. Ekman M, Granstrom O, Omerov S, Jacob J, Landen M. The societal cost of schizophrenia in Sweden. J Ment Health Policy Econ. 2013;16(1): $13-25$.

33. Frey $\mathrm{S}$. The economic burden of schizophrenia in Germany: a populationbased retrospective cohort study using genetic matching. Eur Psychiatry. 2014;29:479-489.

34. Garattini L. Direct costs of schizophrenia in Italian community psychiatric services. Pharmacoeconomics. 2001;19(12):1217-1225.
35. Garattini L, Barbui C, Clemente R, Cornago D, Parazzini F. Direct costs of schizophrenia and related disorders in Italian community mental health services: a multicenter, prospective 1-year followup study. Schizophr Bull. 2004;30(2):295-302.

36. Guest JF, Cookson RF. Cost of schizophrenia to UK society: an incidence-based cost-of-illness model for the first 5 years following diagnosis. Pharmacoeconomics. 1999;15(6):597-610.

37. Haro JM, Salvador-Carulla L, Cabases J, Madoz V, Vazquez-Barquero JL. Utilisation of mental health services and costs of patients with schizophrenia in three areas of Spain. Br J Psychiatry. 1998;173: 334-340.

38. Heider D, Bernert S, Konig HH, et al. Direct medical mental health care costs of schizophrenia in France, Germany and the United Kingdom Findings from the European Schizophrenia Cohort (EuroSC). Eur Psychiatry. 2009;24(4):216-224.

39. Hertzman P. The economic costs of mental illness in Sweden 1975. Acta Psychiatr Scand. 1983;68(5):359-367.

40. Knapp M, Chisholm D, Leese M, et al. Comparing patterns and costs of schizophrenia care in five European countries: The EPSILON study. Acta Psychiatr Scand. 2002;105(1):42-54.

41. Lindstrom E, Eberhard J, Neovius M, Levander S. Costs of schizophrenia during 5 years. Acta Psychiatr Scand Suppl. 2007;116:33-40.

42. Mangalore R, Knapp M. Cost of schizophrenia in England. J Ment Health Policy Econ. 2007;10(1):23-41.

43. Oliva-Moreno J, Lopez-Bastida J, Osuna-Guerrero R, MontejoGonzalez AL, Duque-Gonzalez B. The costs of schizophrenia in Spain. Eur J Health Econ. 2006;7(3):182-188.

44. Rouillon F. Some aspects of the cost of schizophrenia in France. Pharmacoeconomics. 1997;11(6):578-594.

45. Rund BR, Ruud T. Costs of services for schizophrenic patients in Norway. Acta Psychiatr Scand. 1999;99(2):120-125.

46. Salize HJ, McCabe R, Bullenkamp J, et al. Cost of treatment of schizophrenia in six European countries. Schizophr Res. 2009;111(1-3): $70-77$.

47. Salize HJ, Rossler W. The cost of comprehensive care of people with schizophrenia living in the community. A cost evaluation from a German catchment area. Br J Psychiatry. 1996;169:42-48.

48. Sarlon E, Heider D, Millier A, et al. A prospective study of health care resource utilisation and selected costs of schizophrenia in France. BMC Health Serv Res. 2012;12:269-276.

49. Tarricone R, Gerzeli S, Montanelli R, Frattura L, Percudani M, Racagni G. Direct and indirect costs of schizophrenia in community psychiatric services in Italy: The GISIES study. Health Policy. 2000;51(1):1-18.

50. Vazquez-Polo FJ, Negrin M, Cabases JM, Sanchez E, Haro JM, Salvador-Carulla L. An analysis of the costs of treating schizophrenia in Spain: a hierarchical Bayesian approach. J Ment Health Policy Econ. 2005;8(3):153-165.

51. Zeidler J, Slawik L, Fleischmann J, Greiner W. The costs of schizophrenia and predictors of hospitalisation from the statutory health insurance perspective. Health Econ Rev. 2012;2(1):1-8.

52. Behan C, Kennelly B, O'Callaghan E. The economic cost of schizophrenia in Ireland: a cost of illness study. Irish J Psychol Med. 2008; 25(3):80-87.

53. Evers SM, Ament AJ. Costs of schizophrenia in The Netherlands. Schizophr Bull. 1995;21(1):141-153.

54. Bartels SJ, Clark RE, Peacock WJ, Dums AR, Pratt SI. Medicare and medicaid costs for schizophrenia patients by age cohort compared with costs for depression, dementia, and medically Ill patients. Am J Geriatr Psychiatry. 2003;11(6):648-657.

55. Crown WH, Neslusan C, Russo PA, Holzer S, Ozminkowski R, Croghan T. Hospitalization and total medical costs for privately insured persons with schizophrenia. Adm Policy Ment Health. 2001;28(5): 335-351.

56. Cuffel BJ, Jeste DV, Halpain M, Pratt C, Tarke H, Patterson TL. Treatment costs and use of community mental health services for schizophrenia by age cohorts. Am J Psychiatry. 1996;153(7):870-876. 
57. Desai PR, Lawson KA, Barner JC, Rascati KL. Estimating the direct and indirect costs for community-dwelling patients with schizophrenia. J Pharm Health Ser Res. 2013;4(4):187-194.

58. Dixon L, Lyles A, Smith C, et al. Use and costs of ambulatory care services among medicare enrollees with schizophrenia. Psychiatr Serv. 2001;52(6):786-792.

59. Feldman R, Bailey RA, Muller J, Le J, Dirani R. Cost of schizophrenia in the medicare program. Popul Health Manag. 2014;17(3):190-196.

60. Goeree R, Farahati F, Burke N, et al. The economic burden of schizophrenia in Canada in 2004. Curr Med Res Opin. 2005;21(12):2017-2028.

61. Leslie DL, Rosenheck R. Shifting to outpatient care? Mental health care use and cost under private insurance. Am J Psychiatry. 1999;156(8): $1250-1257$.

62. Martin BC, Miller LS. Expenditures for treating schizophrenia: a population-based study of Georgia medicaid recipients. Schizophr Bull. 1998;24(3):479-488.

63. McDonald M, Hertz RP, Lustik MB, Unger AN. Healthcare spending among community-dwelling adults with schizophrenia. Am J Manag Care. 2005;11:S242-S247.

64. Miller LS, Martin BC. Current and future forecasts of service use and expenditures of Medicaid-eligible schizophrenia patients in the State of Georgia. Schizophr Bull. 2004;30(4):983-995.

65. Rubio-Stipec M, Stipec B, Canino G. The costs of schizophrenia in Puerto Rico. J Ment Health Adm. 1994;21(2):136-144.

66. Leitao RJ, Ferraz MB, Chaves AC, Mari JJ. Cost of schizophrenia: direct costs and use of resources in the State of Sao Paulo. Rev Saude Publica. 2006;40(2):304-309.

67. Wyatt RJ, Henter I, Leary MC, Taylor E. An economic evaluation of schizophrenia-1991. Soc Psychiatry Psychiatr Epidemiol. 1995;30(5): 196-205.

68. Gunderson JG, Mosher LR. The cost of schizophrenia. Am J Psychiatry. 1975;132(9):901-906.

69. de Silva J, Hanwella R, de Silva VA. Direct and indirect cost of schizophrenia in outpatients treated in a tertiary care psychiatry unit. Ceylon Med J. 2012;57(1):14-18.

70. Carr VJ, Neil AL, Halpin SA, Holmes S, Lewin TJ. Costs of schizophrenia and other psychoses in urban Australia: findings from the Low Prevalence (Psychotic) Disorders Study. Aust N Z J Psychiatry. 2003; 37(1):31-40.

71. Grover S, Avasthi A, Chakrabarti S, Bhansali A, Kulhara P. Cost of care of schizophrenia: a study of Indian out-patient attenders. Acta Psychiatr Scand. 2005;112(1):54-63.

72. Hall W, Goldstein G, Andrews G, Lapsley H, Bartels R, Silove D. Estimating the economic costs of schizophrenia. Schizophr Bull. 1985;11(4): 598-610.
73. Lang HC, Su TP. The cost of schizophrenia treatment in Taiwan. Psychiatr Serv. 2004;55(8):928-930.

74. Lee IH, Chen PS, Yang YK, et al. The functionality and economic costs of outpatients with schizophrenia in Taiwan. Psychiatry Res. 2008; 158(3):306-315.

75. Pahuja S, Aboobacker S, Shini VK. Schizophrenia - cost of illness. Int J Pharm Sci Rev Res. 2011;6(1):55-59.

76. Phanthunane P, Whiteford H, Vos T, Bertram M. Economic burden of schizophrenia: empirical analyses from a survey in Thailand. J Ment Health Policy Econ. 2012;15(1):25-32.

77. Sado M, Inagaki A, Koreki A, et al. The cost of schizophrenia in Japan Neuropsychiatr Dis Treat. 2013;9:787-798.

78. Zhai J, Guo X, Chen M, Zhao J, Su Z. An investigation of economic costs of schizophrenia in two areas of China. Int J Ment Health Syst. 2013;7(1):26.

79. Langley-Hawthorne C. Modeling the lifetime costs of treating schizophrenia in Australia. Clin Ther. 1997;19(6):1470-1495.

80. Fitzgerald PB, Montgomery W, de Castella AR, et al. Australian Schizophrenia Care and Assessment Programme: real-world schizophrenia: economics. Aust N Z J Psychiatry. 2007;41(10):819-829.

81. Amoo G, Ogunlesi AO. Financial cost of treating Nigerian in-patients with schizophrenia. Afr J Med Med Sci. 2005;34(1):15-23.

82. Suleiman TG, Ohaeri JU, Lawal RA, Haruna AY, Orija OB. Financial cost of treating out-patients with schizophrenia in Nigeria. $\mathrm{Br} J$ Psychiatry. 1997;171:364-368.

83. Segel JE. Cost-of-illness studies - A primer. RTI-UNC Center of Excellence in Health Promotion Economics. 2006:1-39.

84. Kigozi J, Jowett S, Lewis M, Barton P, Coast J. Estimating productivity costs using the friction cost approach in practice: a systematic review. Eur J Health Econ. 2016;17(1):31-44.

85. O'Shea E, Kennelly B. The Economics of Mental Health Care in Ireland. Dublin: Mental Health Commission; 2008.

86. Lensberg BR, Drummond MF, Danchenko N, Despiégel N, François C Challenges in measuring and valuing productivity costs, and their relevance in mood disorders. Clinicoeconomics Outcomes Res. 2013;5: $565-573$.

87. Millier A, Schmidt U, Angermeyer M, et al. Humanistic burden in schizophrenia: a literature review. J Psychiatr Res. 2014;54:85-93.

88. Hu TW. Perspectives: an international review of the national cost estimates of mental illness, 1990-2003. J Ment Health Policy Econ. 2006;9(1):3-13

89. Freeman P, Robbins A. The publishing gap between rich and poor: the focus of AuthorAID. J Public Health Policy. 2006;27:196-203.
Neuropsychiatric Disease and Treatment

\section{Publish your work in this journal}

Neuropsychiatric Disease and Treatment is an international, peerreviewed journal of clinical therapeutics and pharmacology focusing on concise rapid reporting of clinical or pre-clinical studies on a range of neuropsychiatric and neurological disorders. This journa is indexed on PubMed Central, the 'PsycINFO' database and CAS,

\section{Dovepress}

and is the official journal of The International Neuropsychiatric Association (INA). The manuscript management system is completely online and includes a very quick and fair peer-review system, which is all easy to use. Visit http://www.dovepress.com/testimonials.php to read real quotes from published authors. 